American Journal of Pharmaceutical Education 2021; 85 (3) Article 848116.

\title{
BRIEF
}

\section{Improving Health Professions Students' Understanding of Interprofessional Roles Through Participation in a Patient Stabilization Simulation}

\author{
Lisa F. Brennan, PharmD, ${ }^{\text {a,b }}$ Allison McBride, MD, ${ }^{\mathrm{c}}$ Modupeola Akinola, MD, ${ }^{\mathrm{c}}$ Samantha Ogle, DHA, \\ Jon Goforth, MBA, ${ }^{\mathrm{c}}$ Deb Harding, DNP, ${ }^{\mathrm{b}}$ Kimberly Stanbery, DNP, ${ }^{\mathrm{b}}$ Paula Correa, DNP, \\ Amy Milner, MSN, ${ }^{\text {b }}$ Roy Strowd, MD, MEd, $\mathrm{MS}^{\mathrm{b}, \mathrm{c}}$ \\ ${ }^{a}$ Wingate University, School of Pharmacy, Wingate, North Carolina \\ ${ }^{\mathrm{b}}$ Wake Forest Baptist Medical Center, Winston-Salem, North Carolina \\ ${ }^{\mathrm{c}}$ Wake Forest School of Medicine, Winston-Salem, North Carolina \\ Submitted April 16, 2020; accepted November 15, 2020; published March 2021.
}

\begin{abstract}
Objective. To teach interprofessional communication and teamwork skills to health professions students through a standardized patient simulation on acute patient stabilization and measure the impact on learners' perceptions of interprofessional collaboration.

Methods. Medical and pharmacy students in their final year and post-licensure nurses in their initial six-month probationary period worked together to stabilize a simulated acutely ill standardized patient. Perceptions of IPE were assessed pre- and post-simulation using the Student Perceptions of Interprofessional Clinical Education-Revised Instrument, version 2 (SPICE-R2). Medical student participants' scores were compared to those of a concurrently enrolled cohort of medical students who did not participate in the simulation.

Results. Eighty learners participated in the simulation and all completed pre and post SPICE-R2 assessments. Learners' perceptions increased significantly in all domains, including understanding of roles in collaborative practice, interprofessional teamwork and team-based practice, and patient outcomes from collaborative practice. Compared to the control cohort, participants' perceptions of team-based practice and the impact on patient outcomes improved significantly, while a statistically similar improvement in scores for understanding of roles and responsibilities was seen. The SPICE-R2 scores increased similarly among students in each profession. Repeat exposure to the simulation continued to improve perceptions but not as robustly as the initial simulation.

Conclusion. This simulation changed learners' perceptions of how interprofessional collaboration affects patient care, which supports the incorporation of standardized patient-based interprofessional education even in the late-stage education of health professionals.
\end{abstract}

Keywords: interprofessional education, simulation, bootcamp, collaborative practice, internship preparation, standardized patient

\section{INTRODUCTION}

Complex health care needs require an effective interprofessional health care team with shared goals, clear roles, and effective communication to achieve measurable outcomes. ${ }^{1}$ Failure of health professionals to function effectively as a team leads to adverse patient outcomes and accounts for up to $80 \%$ of serious medical errors. ${ }^{2}$ Successful team collaboration improves patient care, decreases patient length of stay, and reduces health

Corresponding Author: Lisa F. Brennan, Wingate University, School of Pharmacy, 515 N. Main St., Wingate, NC 28174. Tel: 336-713-1937. Email: L.brennan@, wingate.edu care costs. ${ }^{3}$ Developing health professions students' competency in collaboration requires interprofessional education (IPE). In medicine, the percentage of institutions that require IPE activities has risen to $92 \%$, and accrediting bodies for nursing and pharmacy schools require IPE throughout their curricula. ${ }^{4-6}$

The Health Professions Accreditors Collaborative created guidance to develop, implement, and evaluate IPE across a wide range of professions. ${ }^{7,8}$ Four core interprofessional competencies (Values/Ethics for Interprofessional Practice, Roles/Responsibilities, Interprofessional Communication, Teams and Teamwork) provide an outcome-driven framework for understanding what should be taught, assessed, and expected in IPE. ${ }^{4}$ At our institution, a 


\section{American Journal of Pharmaceutical Education 2021; 85 (3) Article 848116.}

needs assessment survey of educational priorities for senior medical students revealed a need for IPE training as a capstone experience immediately prior to students graduating and beginning supervised clinical practice. Specifically, $15 \%$ of graduating medical students requested training in how to achieve Entrustable Professional Activity (EPA) 9, "collaborate as a member of an interprofessional team." Therefore, we developed a didactic session on interprofessional teams and an optional acute patient stabilization simulation to provide learning about team communication and roles and responsibilities, and to observe the impact on outcomes of teamwork in a controlled environment. ${ }^{10-12}$ We describe our assessment of the effect of this standardized-patient simulation workshop on learners' perceptions of interprofessional education, including roles and responsibilities and communication and teamwork, and the impact of these on patient outcomes.

\section{METHODS}

Approval for this study was obtained from the Wake Forest School of Medicine (WFSOM) Institutional Review Board. An interprofessional steering committee consisting of nurses, physicians, pharmacists, an instructional designer, the WFSOM Director of Interprofessional Education, and medical education staff members from two institutions was convened to design, implement, and assess the outcomes of an optional IPE simulation-based workshop. All medical students who participated in the Transition to Residency course received didactic instruction on IPE and were given the opportunity to participate in an IPE simulation. Post-licensure nurses in their six-month orientation period and fourth-year pharmacy students completing experiential rotations were recruited from the health system to participate in the simulation workshop. Because of the limited number of pharmacy students on rotation in the health system they were scheduled to participate in up to three simulations. Data were collected after each simulation to assess the subsequent effects of the simulation.

The primary objective of this study was to determine the impact of an interprofessional patient stabilization simulation on learner perceptions of interprofessional collaboration. Secondary objectives were to compare the change in IPE factors, including roles and responsibilities, communication and teamwork, and impact on patient outcomes pre/post simulation. Exploratory objectives included evaluating the effect of repeated exposure to the simulation on students' perceptions of IPE.

Each simulation required a standardized patient, a fourth-year medical student, an orienting new nurse graduate, a fourth-year pharmacy student, as well as preceptors from each profession. Six simulations ran concurrently and were repeated with a new group of learners every 20 minutes. A group pre-briefing was held to orient all learners to the logistics of the event, although no information about the actual case was provided to participants prior to the simulation.

The simulation case involved a patient with an acute medical crisis requiring immediate stabilization. The 10minute simulation began with a nurse paging the medical student who then entered the simulation room and worked with the pharmacy student and nurse to stabilize the patient. Debriefing was conducted immediately after the simulation inside the simulation room using a standardized team checklist created by the steering committee. The team checklist was intended to prompt formative feedback from preceptors on the communication expected and actions taken by the team to stabilize the standardized patient. The checklist was also used to prompt discussion among participants and preceptors on their perceptions of the simulation.

The assessment tool used to measure the primary and secondary study objectives was the validated 10 -item Student Perceptions of Interprofessional Clinical Education-Revised Instrument, version 2 (SPICE-R2, fivepoint Likert, Cronbach alpha $=.86) .{ }^{13-15}$ This instrument assesses agreement with statements about student perception of interprofessional teamwork and team-based practice, roles and responsibilities for collaborative practice, and patient outcomes from collaborative practice. The primary outcome was the overall SPICE-R2 score, and secondary outcomes were the factor scores. All simulation participants completed the SPICE-R2 immediately before and after the simulation. Pharmacy students who participated in two or three enactments of the simulation completed a second SPICE-R2 after their final (second or third) enactment to assess the impact of repeated exposure to the simulation. Medical students who participated in the simulation workshop (eg, participants) and those who did not participate (eg, controls) completed the SPICE-R2 on day 1 and day 14 of the Transition to Residency course.

A paired Student $t$ test was used to compare pre- and post-survey means and responses of medical students who did and did not participate in the simulation. An ANOVA was conducted to compare the means between the three student groups. Effect size was calculated using the Cohen $d$.

\section{RESULTS}

Eighty learners participated in the simulation and completed the surveys. Fourth-year medical students $(n=41)$, fourth year pharmacy students $(n=17)$, and nursing trainees $(\mathrm{n}=22)$ worked in teams of three to stabilize the acutely ill standardized patient. Nursing trainee 


\section{American Journal of Pharmaceutical Education 2021; 85 (3) Article 848116.}

numbers were lower than expected because of scheduling conflicts on the day of the simulation. Because of this, some nursing students participated in the simulation more than once but only completed one post survey.

Overall, participants' perceptions of IPE were high prior to the intervention. No significant differences were found between learner groups in perceptions of teamwork $(p=.98)$, roles and responsibilities $(p=.81)$, and patient outcomes $(p=.31)$. Perceptions significantly improved after completing the IPE simulation for all learners and for each profession (Table 1). The greatest numerical increase was seen in medical students' SPICE-R2 scores; however, the improvement was not statistically significantly different from nursing or pharmacy participants $(p=.87)$. The perceptions of all learners significantly improved in the individual IPE factors as well, and again no significant difference was detected between learner groups' perceptions of teamwork, roles and responsibilities, or patient outcome.

Pre-course SPICE-R2 scores did not differ between medical students who participated in the simulation workshop and those in the control group who did not participate. Overall mean SPICE-R2 scores for medical student participants increased more than those of control students, though the difference was not significant (Table 2). Medical students in the control group also gained significantly in their perceptions of roles and responsibilities. When comparing scores on the individual SPICER2 factors, mean change in perception was significantly different between student participants compared to control students in the teamwork and team based practice factor as well as the impact of collaborative practice on patient outcomes factor both with medium effect size $(\mathrm{d}=.49$ and .39 respectively). However, there was no significant difference in change in perceptions of effect of collaborative practice on patient outcomes between participants and control students (Table 2).

For pharmacy students who completed more than one simulation, their repeated exposure was less impactful than the initial one. Although the perceptions of these pharmacy students continued to improve numerically with additional patient simulations, this increase was not significant. A trend toward continued improvement in their understanding of roles and responsibilities was present with repeated exposure (Table 3).

\section{DISCUSSION}

This simulation specifically aimed to address perceptions of interprofessional collaboration in health care professionals as they make the transition to clinical practice. There were two major findings from this study. First, we found that health professions students'

Table 1. Participants' Responses on the Student Perceptions of Interprofessional Clinical Education-Revised 2 Instrument Before and After Participation in an Acute Patient Stabilization Simulation

\begin{tabular}{|c|c|c|c|}
\hline & Pre-Simulation, Mean (SD) ${ }^{a}$ & Post-Simulation, Mean (SD) ${ }^{\mathrm{a}}$ & $p$ value \\
\hline \multicolumn{4}{|l|}{ Teamwork } \\
\hline All participants & $4.4(.5)$ & $4.7(.4)$ & $<.001$ \\
\hline Nursing trainees & $4.4(.5)$ & $4.7(.5)$ & .001 \\
\hline Pharmacy students ${ }^{b}$ & $4.4(.5)$ & $4.6(.5)$ & .02 \\
\hline \multicolumn{4}{|l|}{ Roles } \\
\hline Nursing trainees & $3.8(.6)$ & $4.5(.6)$ & $<.001$ \\
\hline Pharmacy students ${ }^{\mathrm{b}}$ & $3.7(.7)$ & $4.1(.7)$ & .009 \\
\hline \multicolumn{4}{|l|}{ Patient Outcomes } \\
\hline All participants & $4.3(.6)$ & $4.6(.5)$ & $<.001$ \\
\hline Medical students & $4.2(.6)$ & $4.6(.5)$ & $<.001$ \\
\hline All participants & $4.2(.4)$ & $4.6(.4)$ & $<.001$ \\
\hline Medical students & $4.1(.1)$ & $4.6(.1)$ & $<.001$ \\
\hline Nursing trainees & $4.2(.1)$ & $4.6(.1)$ & $<.001$ \\
\hline Pharmacy students ${ }^{b}$ & $4.2(.1)$ & $4.4(.1)$ & .002 \\
\hline
\end{tabular}

${ }^{\mathrm{a}}$ Mean (SD) of responses (based on a five-point Likert scale) on the Student Perceptions of Interprofessional Clinical Education-Revised Instrument, version 2 (SPICE-R2)

${ }^{\mathrm{b}}$ Data for pharmacy students compared after the first simulation 


\section{American Journal of Pharmaceutical Education 2021; 85 (3) Article 848116.}

Table 2. Medical Student Responses on the Student Perceptions of Interprofessional Clinical Education-Revised 2 Instrument Day 1 and Day 14 of the Transition to Residency Course

\begin{tabular}{|c|c|c|c|c|c|c|}
\hline Participated in Simulation & Day 1, M (SD) & Day 14, M (SD) & $p$ value $^{\mathrm{a}}$ & $\begin{array}{l}\text { Mean of all } \\
\text { differences }\end{array}$ & $p$ value $^{\mathrm{b}}$ & Cohen's d ${ }^{\mathrm{c}}$ \\
\hline \multicolumn{7}{|l|}{ Overall } \\
\hline Did Participate & $4.2(.5)$ & $4.2(.5)$ & .13 & .12 & .10 & .33 \\
\hline Did not & $4.1(.5)$ & $4.1(.5)$ & .57 & -.03 & & \\
\hline \multicolumn{7}{|l|}{ Teamwork } \\
\hline Did Participate & $4.3(.7)$ & $4.4(.5)$ & .31 & .09 & .02 & .49 \\
\hline Did not & $4.3(.5)$ & $4.1(.6)$ & .008 & -.17 & & \\
\hline \multicolumn{7}{|l|}{ Roles } \\
\hline Did Participate & $3.9(.6)$ & $4.0(.5)$ & .21 & .12 & .62 & .10 \\
\hline Did not & $3.8(.7)$ & $4.0(.6)$ & .01 & .18 & & \\
\hline \multicolumn{7}{|l|}{ Outcomes } \\
\hline Did Participate & $4.1(.6)$ & $4.3(.6)$ & .33 & .15 & .047 & .39 \\
\hline Did not & $4.1(.7)$ & $4.0(.7)$ & .10 & -.06 & & \\
\hline
\end{tabular}

$\mathrm{M}$ is mean with standard deviation (SD) of 5-point Likert scale responses on the Student Perceptions of Interprofessional Clinical EducationRevised Instrument, version 2 (SPICE-R2)

Mean of all differences is of differences in scores on the SPICE-R2 for all students who did and did not participate in the simulation on day 1 and day 14

${ }^{a}$ Two-sided $p$ value calculated by paired student's t test between day 1 and day 14 means with significance defined as $p<.05$

${ }^{\mathrm{b}}$ Two-sided $p$ value calculated by paired student's t test between the means of all differences of students who did and did not participate with significance defined as $p<.05$

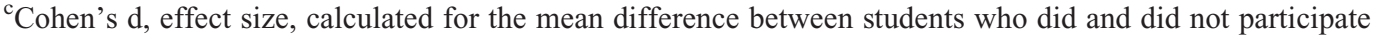

perception of team-based care and its impact on patient outcomes was significantly improved as a result of participation in this workshop compared to the perception of medical students in a control group who only received didactic IPE. Second, learners from all of the health care professions represented benefitted similarly from participation, thereby fulfilling key criteria for IPE.

The IPE simulation was feasible and impactful for medical, nursing, and pharmacy learners immediately prior to their transition to clinical practitioner. These findings add to a growing body of literature on the importance and impact of interprofessional training for health professions learners. ${ }^{16-19}$ This transition to clinical practice is an important time to incorporate IPE as learners have had an opportunity to witness collaborative care during clinical practicum experiences and understand the need to collaborate with other health professionals when they enter practice.

Prior to this workshop, participants' understanding of roles was the lowest of the three IPE factors that were assessed, even though this factor is foundational and a key first step in interprofessional collaboration. All medical students and pharmacy students in our study had previously been exposed to IPE curricula that taught interprofessional responsibilities and roles, yet prior to the simulation this was still an area in which improvement was needed. In our study, all participants' understanding of their professional roles and responsibilities when caring for a patient as part of a health care team improved. These findings suggest that students immediately prior to graduation and licensure can benefit from further instruction on identifying other professionals, understanding their role at the patient's bedside, and appreciating how this understanding influences delivery of team-based

Table 3. Pharmacy Student Responses on the Student Perceptions of Interprofessional Clinical Education-Revised 2 Instrument Before and After Participation in Acute Patient Stabilization Simulations

\begin{tabular}{lcccccc}
\hline & Pre, M (SD) & $\begin{array}{c}\text { Post 1, } \\
\text { M (SD) }\end{array}$ & $\begin{array}{c}\text { Post 2, } \\
\text { M (SD) }\end{array}$ & $\begin{array}{c}p \text { value: pre } \\
\text { to post 1 }\end{array}$ & $\begin{array}{c}p \text { value: post 1 } \\
\text { to post 2 }\end{array}$ & $\begin{array}{c}p \text { value: pre } \\
\text { to post 2 }\end{array}$ \\
\hline Overall & $4.2(.1)$ & $4.4(.1)$ & $4.5(.4)$ & $<.01$ & .08 & $<.001$ \\
Teamwork & $4.4(.5)$ & $4.6(.5)$ & $4.7(.5)$ & .02 & .35 & .005 \\
Roles & $3.7(.7)$ & $4.1(.7)$ & $4.2(.7)$ & $<.01$ & .06 & .001 \\
Outcomes & $4.4(.5)$ & $4.5(.5)$ & $4.7(.5)$ & .03 & .14 & .007 \\
\hline
\end{tabular}




\section{American Journal of Pharmaceutical Education 2021; 85 (3) Article 848116.}

care. Preceptors in our simulation reported that the vast majority of participants did not introduce themselves and this appeared to limit the quality of communication at the bedside. Those students who quickly and efficiently identified all care team members by name garnered greater trust within the group and opened lines of communication. Students also indicated that they were able to observe the link between team communication and patient outcomes in this acute interprofessional crisis management situation. Though participating in the event more than once did not lead to further significant improvement in pharmacy students' perceptions, the improvement numerically continued to increase. This could indicate that participating in multiple events instead of concentrating learning in one session would be more helpful for students. A surprising outcome was the significant increase in perceptions of roles and responsibilities by the group of medical students who did not participate in the simulation while those that did participate did not significantly improve. This may have been the result of a humbling effect that the simulation had on those who participated as they realized they did not know as much about other professions as they had previously thought.

Our study had several strengths. First, we included three different professions in the training exercise, which allowed for a more realistic simulation. Next, we used a validated instrument that was simple to answer to assess participants' learning, which led to high response rates. Another strength is that we included a control medical student cohort, allowing for comparison of the effects of didactic IPE vs didactic plus simulation. Also, an interprofessional facilitator-led debrief was held immediately after the simulation, which has been proven to be a more effective method than self-learning to ensure the IPE activity had the desired impact. ${ }^{20}$

Study limitations include the lack of standardized preparation of both facilitators and learners. As a result, some of the learners were unclear about the goals for the activity. Also, the facilitators might have debriefed their groups differently, although we attempted to control for this by using a team checklist. This may have led to differences in the impact the workshop had on the learners. Second, our study outcomes were based on learner perceptions and knowledge of interprofessional collaboration (the most basic impacts of IPE) rather than on changes in behavior. ${ }^{20} \mathrm{~A}$ further limitation of the study was in allowing medical students to self-select to participate. This may have resulted in bias in the outcomes as those students who did not participate may have been overconfident in their interprofessional skills.

An area for further research into instruction of health professions students on interprofessional roles is the effect of the structured debriefing held after the simulation. Team debriefing is a critical opportunity to teach, learn, and demonstrate the value of interprofessional team-based education. Additionally, follow-up data to measure this simulation's effect on the learners' behavior once they enter practice would greatly add to the literature.

\section{CONCLUSION}

In this study, we demonstrated that a simulationbased IPE activity focusing on bedside communication and collaboration between medical students, pharmacy students, and novice nurses significantly improved trainees' perception of collaborative teamwork, understanding of the roles and responsibilities of the care team, and recognition of the improved patient outcomes achievable through collaboration. Standardized patient IPE simulations are a feasible and relevant instructional method in late-stage training of health care professionals prior to clinical practice. Further research on the effects of a structured debrief on participants' attitudes toward IPE and comparison of post-intervention assessment scores to those of a diverse IPE control group would further inform the use of simulation.

\section{REFERENCES}

1. Babiker A, El Husseini M, Al Nemri A, et al. Health care professional development: working as a team to improve patient care. Sudan J Paediatr. 2014;14(2):9-16.

2. Mayo AT, Woolley AW. Teamwork in health care: maximizing collective intelligence via inclusive collaboration and open communication. AMA J Ethics. 2016;18(9):933-940. doi: 10.1001/ journalofethics.2016.18.9.stas2-1609.

3. Mickan SM. Evaluating the effectiveness of health care teams. Aust Health Rev. 2005;29(2):211-217.

4. Interprofessional Education Collaborative. Core competencies for interprofessional collaborative practice: 2016 update. Washington, DC: Interprofessional Education Collaborative. https:// nebula.wsimg.com/2f68a39520b03336b41038c370497473? AccessKeyId = DC06780E69ED19E2B3A5\&disposition $=0 \&$ alloworigin=1. Accessed March 2, 2021.

5. Standards for Accreditation of Baccalaureate and Graduate Nursing Programs. Commission on Collegiate Nursing Education. 2018. https://www.aacnnursing.org/Portals/42/CCNE/PDF/ Standards-Final-2018.pdf. Accessed March 2, 2021.

6. Accreditation Standards and Key Elements for the Professional Program in Pharmacy Leading to the Doctor of Pharmacy Degree. Accreditation Council for Pharmacy Education. 2016. https:// www.acpe-accredit.org/pdf/Standards2016FINAL.pdf. Accessed March 2, 2021.

7. Health Professions Accreditors Collaborative. Guidance on developing quality interprofessional education for the health professions. 2019. Chicago, IL: Health Professions Accreditors Collaborative. https://healthprofessionsaccreditors.org/wp-content/ uploads/2019/02/HPACGuidance02-01-19.pdf. Accessed March 2, 2021. 


\section{American Journal of Pharmaceutical Education 2021; 85 (3) Article 848116.}

8. Spaulding EM, Marvel FA, Jacob E, et al. Interprofessional education and collaboration among healthcare students and professionals: a systematic review and call for action. $J$ Interprof Care. 2019;1-10. doi: 10.1080/13561820.2019.1697214

9. Strowd RE, McBride A, Goforth J, et al. Educational priorities of students in the entrustable professional activity era. Clin Teach. 2018; 15:319-324. doi: 10.1111/tct.12688

10. Palaganas JC, Epps C, Raemer DB. A history of simulationenhanced interprofessional education. $J$ Interprof Care. 2014;28(2): 110-115. doi: 10.3109/13561820.2013.869198

11. Blackmore A, Kasfiki EV, Purva M. Simulation-based education to improve communication skills: a systematic review and identification of current best practice. BMJ Simul Technol Enhanc Learn. 2018;4:159-164. http://dx.doi.org/10.1136/bmjstel-2017000220

12. Zamjahn JB, Beyer EO, Alig KL, et al. Increasing awareness of the roles, knowledge, and skills of respiratory therapists through an interprofessional education experience. Respir Care. 2018 May; 63(5):510-518. doi: 10.4187/respcare.05869

13. Fike DS, Zorek JA, MacLaughlin AA, Samiuddin M, Young RB, MacLaughlin EJ. Development and validation of the Student Perceptions of Physician-Pharmacist Interprofessional Clinical Education (SPICE) instrument. Am J Pharm Educ. 2013;77(9): Article 190. doi: 10.5688/ajpe779190 14. Zorek JA, Fike DS, Eickhoff JC, et al. Refinement and validation of the Student Perceptions of Interprofessional Clinical Education
Instrument. Am J Pharm Educ. 2016;80(3):Article 47. doi: 10.5688/ ajpe 80347

15. Dominguez DG, Fike DS, MacLaughlin EJ, Zorek JA. A comparison of the validity of two instruments assessing health professional student perceptions of interprofessional education and practice. J Interprof Care. 2015; 29(2):144-149. doi: 10.3109/ 13561820.2014.947360

16. Brisolara KF, Culbertson R, Levitzky E, et al. Supporting health system transformation: the development of an integrated interprofessional curriculum inclusive of public health students. $J$ Health Adm Educ. 2019;36(1):111-121.

17. Brisolara KF, Gasparini S, Davis AH, et al. Supporting health system transformation through an interprofessional education experience focused on population health. $J$ Interprof Care. 2019; 33(1):125-128. doi: 10.1080/13561820.2018.1530646

18. Murdoch NL, Epp S, Vinek J. Teaching and learning activities to educate nursing students for interprofessional collaboration: a scoping review. J Interprof Care. 2017;31(6):744-753. doi: 10.1080/ 13561820.2017.1356807

19. Doucet S, Loney E, Brown PA. Perceptions of graduating health professional students of their interprofessional education experiences during pre-licensure education. J Allied Health. 2016;45(2):e5-9.

20. Reeves S, Fletcher S, Barr H, et al. A BEME systematic review of the effects of interprofessional education: BEME Guide No. 39. Med Teach. 2016;38(7):656-668. doi:10.3109/ 0142159X.2016.1173663 